\title{
Evaluasi Penerapan Metode Pembelajaran Berpusat pada Mahasiswa (Student Centered Learning) pada Program Studi Ilmu Gizi Fakultas Kedokteran Masyarakat Universitas Hasanudin
}

\author{
Aminuddin*, Gandes Retno Rahayu**, E. Suryadi** \\ * $\quad$ Fakultas Kedokteran Masyarakat, Universitas Hasanudin, Makasar \\ ** Program Studi S2 Ilmu Pendidikan Kedokteran Fakultas Kedokteran Universitas Gadjah Mada
}

\begin{abstract}
Background: Shifting method from teaching to learning approaches require students to take the initiative to learn more, while academic staff only acts as a facilitator and requires them to be able to manage learning activities well. Thus it is necessary for them to know several methods of essential student centered learning so they can select the most suitable type of learning method to achieve the learning competencies from a single subject.

Objective: To evaluate academic staff knowledge, students of Nutrition Department, Faculty of Public Health class of 2008 and 2009 and supporting staffs knowledge about student learning centered method.

Method: This research was conducted with the mixed method (embedded design, qualitative research as part of the quantitative research) with a primary emphasis on quantitative research involving all students of class 2008 and 2009, who are still in the academic phase, academic staff of nutritional department and supporting staff of Faculty of Public Health, Hasanuddin University.

Result and Discussion: There are 3 methods most answer correctly by 54,5\% of respondents that the advantages of using small group discussion, advantages of cooperative learning and problem based learning weaknesses. While the least correct answer is the advantage of problem-based learning method that is 4,5\% respondents.

For open questions, the most preferred methods are small group of, 18,2\%; case studies of $18,2 \%$ and PBL of $13,6 \%$. While the least preferred methods are cooperative learning and discovery learning $13,6 \%$, respectively. This question is actually an open question so there were $27,3 \%$ of the respondents that did not answer; the preferred method or not. Conclusion: Respondents generally knew and heard the term SCL through correspondence, newspaper and faculty meetings. Respondents define SCL as learning with computers, in small rooms or some sort of FGD. In terms of the benefits of SCL respondents define it variously; to develop the potential and motivation of students, students more actively seek and accept; provide opportunities for students to obtain more sources, students find it easier to find lecture material"; student is more serious in his courses"; students more active in the lecture"; students are more self-sufficient". Efforts made for the implementation of the SCL, according to in formant sare facilitating room equipments, props and LCD; expedite the administrative process; monitoring, inserting topics, and being ontime in the implementation of lecturers and improvementals of academic staff.
\end{abstract}

Keywords: academic staff knowledge, students and supporting staffs perception. SCL

\section{ABSTRAK}

Latar Belakang: Pergeseran pendekatan dari pengajaran ke pembelajaran mengharuskan mahasiswa lebih mengambil inisiatif untuk belajar, sedangkan dosen hanya berfungsi sebagai fasilitator saja. Hal ini mengharuskan dosen untuk mampu mengelola kegiatan pembelajaran dengan baik. Dosen perlu mengetahui beberapa metode esensial pembelajaran yang berpusat pada pembelajar (student centered learning). Pengenalan model pembelajaran diharapkan dapat membantu dosen dalam memilih jenis metode pembelajaran yang paling sesuai untuk mencapai kompetensi pembelajaran yang ingin dicapai dari satu mata kuliah.

Korespondensi: amin_gzuh@yahoo.co.id 
Tujuan:Untuk mengetahui pengetahuan dosen, persepsi mahasiswa Program Studi Ilmu Gizi FKM Unhas angkatan 2008 dan 2009 dan tenaga kependididkan terhadap penerapan metode pembelajaran yang berpusat pada mahasiswa (student centered learning)

Metode: Penelitian ini dilakukan dengan mixed method (embedded design), penelitian kualitatif sebagai bagian dari penelitian kuantitatif) dengan penekanan utama pada penelitian kuantitatif dengan melibatkan seluruh mahasiswa angkatan 2008 dan 2009 yang terdaftar dan aktif mengikuti perkuliahan, dosen program studi ilmu gizi dan tenaga kependidikan FKM Unhas.

Hasil dan Pembahasan: Ada 3 metode yang paling banyak dijawab benar oleh 54,5\% responden yakni kelebihan metode small grup discussion, kelebihan cooperative learning dan kelemahan problem based learning. Sedangkan yang paling sedikit dijawab benar adalah kelebihan metode problem based learning yakni 4,5\% responden.

Untuk pertanyaan terbuka, menggambarkan bahwa metode yang paling disukai oleh responden adalah small group 18,2\%; studi kasus 18,2\% dan PBL 13,6\%. Metode SCL yang yang tidak disukai adalah cooperative learning dan discovery learning yakni masing-masing $13,6 \%$. Pertanyaan ini sebenarnya adalah pertanyaan terbuka sehingga ada $27,3 \%$ responden tidak memberikan jawaban baik metode yang disukai maupun yang tidak disukai.

Kesimpulan: Umumnya informan mengetahui dan mendengar istilah SCL melalui persuratan, suratkabar kampus dan rapat-rapat. Informan mengartikan SCL dengan pembelajaran dengan komputer, ruangan kecil atau semacam FGD. Dalam hal manfaat SCL, informan mengartikannya sangat variatif seperti mengembangkan potensi dan motivasi mahasiswa, mahasiswa lebih aktif mencari dan menerima serta memberikan peluang kepada mahasiswa untuk lebih banyak sumber yang diperoleh, memudahkan mahasisswa untuk mencari materi perkuliahan, mahasiswa lebih serius dalam mata kuliahnya, mahasiswa lebih aktif dalam kuliah, mahasiswa semakin mandiri. Upaya yang dilakukan untuk pelaksanaan SCL, menurut informan adalah memfasilitasi, penyediaan ruangan, alat peraga dan LCD; memperlancar proses administrasi; memantau dan monitoring, memasukkan topik bahasan dan on time dalam pelaksanaan perkuliahan dan memperbaiki mental.

Kata Kunci: pengetahuan dosen, persepsi mahasiswa dan tenaga kependidikan SCL

\section{PENDAHULUAN}

Pengetahuan adalah hasil dari tahu, yang terjadi setelah orang melakukan penginderaan terhadap suatu objek tertentu Pengukuran pengetahuan dapat dilakukan dengan wawancara atau angket yang menanyakan tentang isi materi yang ingin diukur dari subyek penelitian atau responden. ${ }^{1,2}$ Persepsi merupakan suatu proses dimana individu mengorganisasikan dan menginterpretasikan pesan-kesan sensori mereka untuk memberi makna lingkungannya. Persepsi adalah suatu proses pengenalan atau identifikasi sesuatu dengan menggunakan panca indera. Persepsi sebagai aktifitas yang memungkinkan manusia mengendalikan rangsangan-rangsangan yang sampai kepadanya melalui alat inderanya, menjadikannya kemampuan itulah dimungkinkan individu mengenali melalui (lingkungan pergaulan) hidupnya. ${ }^{3}$ Student-centered learning adalah suatu model pembelajaran yang menempatkan peserta didik sebagai pusat dari proses belajar. Model pembelajaran ini berbeda dari model belajar Instructor-centered learning yang menekankan pada transfer pengetahuan dari guru ke murid yang relatif bersikap pasif. Dalam menerapkan konsep student-centered learning, peserta didik diharapkan sebagai peserta aktif dan mandiri dalam proses belajarnya, yang bertanggung jawab dan berinisiatif untuk mengenali kebutuhan belajarnya, menemukan sumbersumber informasi untuk dapat menjawab kebutuhannya, membangun serta mempresentasikan pengetahuannya berdasarkan kebutuhan serta sumber-sumber yang ditemukannya. Dalam batas-batas tertentu peserta didik dapat memilih sendiri apa yang akan dipelajarinya. ${ }^{4}$

Dalam konteks metode pembelajaran SCL, ada 8 ragam metode yang disajikan untuk menilai pengetehuan dosen dan persepsi mahasiswa, yakni small group, role play, case study, discovery learning, cooperative learning, collaborative learning, project based learning dan problem based learning. 5,6,7,8,9,10, 
Sejak tahun 2008, beberapa mata kuliah diujicobakan berbagai metode SCL. Ragam metode SCL yang diterapkan oleh dosen di bagian gizi FKM Unhas berbeda antara mata kuliah atau pokok bahasan dalam satu mata kuliah, sehingga tidak memungkinkan untuk menilai efektifitas dengan hanya satu metode. Oleh karena itu peneliti ingin meneliti tentang pengetahuan dosen dan persepsi mahasiswa dan tenaga kependidikan program studi Ilmu Gizi FKM Unhas terhadap penerapan metode pembelajaran yang berpusat pada mahasiswa (SCL).

\section{TUJUAN PENELITIAN}

Penelitian ini bertujuan untuk mengetahui: (1) gambaran pengetahuan dosen Program Studi Ilmu Gizi FKM Unhas terhadap penerapan metode pembelajaran SCL, (2) gambaran persepsi mahasiswa Program Studi Ilmu Gizi FKM Unhas terhadap penerapan metode pembelajaran SCL, (3) gambaran persepsi tenaga kependidikan Program Studi Ilmu Gizi FKM Unhas terhadap penerapan metode pembelajaran SCL

\section{METODE PENELITIAN}

Metode penelitian yang digunakan adalah mixed method (embedded design, penelitian kualitatif sebagai bagian dari penelitian kuantitatif) dengan penekanan utama pada penelitian kuantitatif. Subjek penelitian adalah mahasiswa program studi ilmu gizi FKM Unhas angkatan 2008 dan 2009 sebanyak 168 orang. Dosen program studi ilmu gizi FKM Unhas sebanyak 22 orang dan tenaga kependidkan FKM Unhas sebanyak 7 orang. Cara pengumpulan data dengan menggunakan kuisioner bagi mahasiswa dan dosen sedangkan tenaga kependidikan menggunakan metode Focus Group Discussion (FGD). Kuisioner untuk mahasiswa telah diuji dengan validitas dan realibilitas kepada 30 orang mahasiswa sebelum dibagikan kepada responden.

Analisis data deskriptif digunakan untuk mengetahui persentase tentang penegetahuan dosen dan persepsi mahasiswa, sedangkan tenaga kependidikan digunakan konten analisis.

\section{HASIL DAN PEMBAHASAN}

1. Karakteristik Umum Responden/Informan

Pada penelitian ini responden mahasiswa terdiri dari laki-laki 10,7\% sedangkan perempuan $89,3 \%$ yang terdiri dari angkatan 2008 sebanyak 54,2\% dan 45,8\% angkatan 2009. Dosen terdiri dari 40,9\% laki-laki dan $59,1 \%$ perempuan. Sedangkan tenaga kependidikan 42,8\% laki-laki dan $57,2 \%$ perempuan.

2. Gambaran Pengetahuan Dosen terhadap Metode Pembelajaran SCL.

Tabel 1. Distribusi metode pembelajaran SCL yang dijawab benar

\begin{tabular}{|c|c|c|c|}
\hline \multirow{2}{*}{ Pernyataan benar } & \multirow{2}{*}{ Metode SCL } & \multicolumn{2}{|c|}{ Jumlah yang benar } \\
\hline & & $\mathrm{n}$ & $\%$ \\
\hline $\begin{array}{l}\text { Pemecahan masalah berdasarkan keputusan bersama, } \\
\text { mahasiswa lebih aktif, digunakan pada perluasan } \\
\text { pengetahuan yang telah ada, dapat mengidentifikasi } \\
\text { dan memecahkan masalah }\end{array}$ & Small group & 12 & 54,5 \\
\hline $\begin{array}{l}\text { Butuh banyak waktu dan perencanaan yang baik, } \\
\text { kurang efektif bila pelaksanaannya berjalan kaku }\end{array}$ & Small group) & 7 & 31,8 \\
\hline $\begin{array}{l}\text { Memberikan pengalaman, kesempatan bagi mahasiswa } \\
\text { untuk mempraktekkan teori, menentukan masalah } \\
\text { yang mungkin terjadi dalam pelaksanaan }\end{array}$ & Role play & 7 & 31,8 \\
\hline $\begin{array}{l}\text { Butuh fasilitas dan peralatan pembelajaran khusus, } \\
\text { waktu yang lama, dan butuh pengalaman lebih pada } \\
\text { topik }\end{array}$ & Role play & 6 & 27,3 \\
\hline $\begin{array}{l}\text { Mengembangkan keterampilan berfikir dan baik bagi } \\
\text { mahasiswa yang memilki pengetahuan cukup terhadap } \\
\text { masalah tertentu }\end{array}$ & Studi kasus & 5 & 22,7 \\
\hline
\end{tabular}


Lanjutan Tabel 1. Distribusi metode pembelajaran SCL yang dijawab benar

\begin{tabular}{|c|c|c|c|}
\hline \multirow{2}{*}{ Pernyataan benar } & \multirow{2}{*}{ Metode SCL } & \multicolumn{2}{|c|}{ Jumlah yang benar } \\
\hline & & n & $\%$ \\
\hline $\begin{array}{l}\text { Sulit mendapatkan kasus yang sesuai, kurang efektif } \\
\text { jika jumlah mahasiswa banyak dan butuh biaya besar }\end{array}$ & Studi kasus & 7 & 31,8 \\
\hline $\begin{array}{l}\text { Membantu dalam menentukan fakta dan keterkaitan } \\
\text { nya, memberi pengalaman bagi mahasiswa, mem } \\
\text { bangkitkan semangat belajar dan meningkatkan } \\
\text { kreativitas. }\end{array}$ & Discovery learning & 8 & 36,4 \\
\hline $\begin{array}{l}\text { Butuh biaya pengembangan yang tinggi, potensi } \\
\text { kesalahan persepsi yang besar, dapat menyebabkan } \\
\text { kejenuhan berpikir }\end{array}$ & Discovery learning & 8 & 36,4 \\
\hline $\begin{array}{l}\text { Meningkatkan kerja sama belajar, memberikan } \\
\text { pengalaman dengan saling berbagi }\end{array}$ & Cooperative learning & 12 & 54,2 \\
\hline $\begin{array}{l}\text { Butuh pengetahuan yang memadai sebelum meng- } \\
\text { gunakan metode ini, mahasiswa dituntut mandiri }\end{array}$ & Cooperative learning & 9 & 40,9 \\
\hline $\begin{array}{l}\text { Meningkatkan kerja sama mahasiswa dalam pemecah } \\
\text { an suatu masalah bcrsama }\end{array}$ & $\begin{array}{c}\text { Collaborative } \\
\text { learning }\end{array}$ & 2 & 9,1 \\
\hline Butuh kerja sama mahasiswa, mahasiswa harus aktif & $\begin{array}{c}\text { Collaborative } \\
\text { learning }\end{array}$ & 9 & 40,9 \\
\hline $\begin{array}{l}\text { Mengembangkan kemampuan berfikir, memberi } \\
\text { pengetahuan dan keterampilan sekaligus,mahasiswa } \\
\text { n1mun menerapkan keteranpilan dan manajenen } \\
\text { diri serta mengembangkan kebiasaan berpikir }\end{array}$ & $\begin{array}{c}\text { Project based } \\
\text { learning }\end{array}$ & 6 & 27,3 \\
\hline $\begin{array}{l}\text { Butuh persiapan dan kesiapan dari dosen dan maha } \\
\text { siswa, butuh biaya tinggi, kurang tepat diterapkan } \\
\text { pada mahasiswa tingkat awal }\end{array}$ & $\begin{array}{c}\text { Project hased } \\
\text { learning }\end{array}$ & 9 & 40,9 \\
\hline $\begin{array}{l}\text { Cukup menantang dan terbuka, jawaban masalah } \\
\text { tidak tunggal, mahasiswa aktif dalam mencari solusi }\end{array}$ & $\begin{array}{c}\text { Problem based } \\
\text { learning }\end{array}$ & 1 & 4,5 \\
\hline $\begin{array}{l}\text { Butuh pengalaman belajar terkait kasusnya, dosen } \\
\text { kesulitan mentransfer ilmu seperti metode konvensio } \\
\text { nal, menantang dan butuh kerja keras. }\end{array}$ & $\begin{array}{c}\text { Problem based } \\
\text { learning }\end{array}$ & 12 & 54,5 \\
\hline
\end{tabular}

Pada tabel 1 menggambarkan bahwa ada 3 metode yang paling banyak dijawab benar oleh $54,5 \%$ responden yakni kelebihan metode small grup discussion, kelebihan cooperative learning dan kelemahan problem based learning. Sedangkan yang paling sedikit dijawab benar adalah kelebihan metode problem based learning yakni $4.5 \%$ responden.
Tabel 2. Distribusi metode pembelajaran yang disukai oleh dosen

\begin{tabular}{lcc} 
Metode Yang Disukai & $\mathbf{n}$ & $\%$ \\
\hline 1. Colluborative leurning & 1 & 4,5 \\
2. Disesuaikan dengan kompetensi & 1 & 4,5 \\
3. Diskusi dan praktek & 1 & 4,5 \\
4. Group discussion & 1 & 4,5 \\
5. Problem based learning & 3 & 13,6 \\
6. Role play & 1 & 4,5 \\
7. Small group discussion & 4 & 18,2 \\
8. Small group discussion, study kasus, & 1 & 4,5 \\
$\quad$ role play & & \\
9. Small group discussion, studi kasus, & 1 & 4.5 \\
$\quad$ PBL & & \\
10. Study kasus & 4 & 18.2 \\
11. Tidak menjawab & 4 & 18,2 \\
\hline Total & 22 & 100 \\
\hline
\end{tabular}

Sumber: Data Primer 
Pada tabel 2 dengan menggunakan pertanyaan terbuka, maka terungkap bahwa metode SCL yang paling disukai dosen adalah Small group discussion, study kasus dan PBL yakni masing-masing $18,2 \%, 18,2 \%$ dan $13,6 \%$.
Pada tabel 3 metode SCL yang tidak disukai adalah cooperative learning dan discovery learning yakni masingmasing $13,6 \%$. Terdapat $18,2 \%$ responden yang tidak memberi jawaban tentang metode SCL yang disukai dan $27,3 \%$ yang tidak memberikan jawaban tentang metode yang tidak disukai

Tabel 3. Distribusi metode pembelajaran yang tidak disukai oleh dosen

\begin{tabular}{lcc} 
Tidak Disukai & & \\
\hline \multicolumn{1}{c}{ Metode } & $\mathbf{n}$ & $\%$ \\
\hline Ceramah & 2 & 9,1 \\
Ceramah tanya jawab & 1 & 4,5 \\
Pembelajaran kolaboratif & 2 & 9,1 \\
Pembelajaran koperatif & 3 & 13,6 \\
Pembelajaran discovery & 3 & 13,6 \\
PBL & 1 & 4,5 \\
Pembelajaran project based & 2 & 9,1 \\
Pembelajaran role play & 2 & 9,1 \\
Tidak menjawab & 6 & 27,3 \\
\hline Total & 22 & 100 \\
\hline
\end{tabular}

Sumber: Data Primer

3. Gambaran Persepsi Mahasiswa terhadap metode pembelajaran SCL

Tabel 4. Distribusi metode SCL yang diterapkan berdasarkan Persepsi Mahasiswa

\begin{tabular}{|c|c|c|c|c|c|}
\hline \multirow{2}{*}{ No. } & \multirow{2}{*}{ Pernyataan } & \multicolumn{2}{|c|}{ Positif } & \multicolumn{2}{|c|}{ Negatif } \\
\hline & & $\bar{n}$ & $\%$ & $\mathrm{n}$ & $\%$ \\
\hline 1. & $\begin{array}{l}\text { Metode pembelajaran ini } \\
\text { mendukung saya untuk mencapai } \\
\text { kompetensi }\end{array}$ & 151 & 89,9 & 17 & 10,1 \\
\hline 2. & $\begin{array}{l}\text { Metode pembelajaran tersebut } \\
\text { menekankan pada partisipasi aktif } \\
\text { dan interaksi sesama kelompok } \\
\text { belajar. }\end{array}$ & 160 & 95,2 & 8 & 4,8 \\
\hline 3. & $\begin{array}{l}\text { Pcmbclajaran dengan metode ini } \\
\text { membutuhkan banyak waktu dan } \\
\text { kurang efektif jika jumlah } \\
\text { mahasiswa besar. }\end{array}$ & 110 & 65,5 & 58 & 34,5 \\
\hline 4. & $\begin{array}{l}\text { Saya lebih leluasa bertanya atau } \\
\text { memberi pendapat jika } \\
\text { menggunakan metode ini. }\end{array}$ & 149 & 88,7 & 19 & 11,3 \\
\hline 5. & $\begin{array}{l}\text { Saya merasa terlatih untuk } \\
\text { mengembangkan keterampilan } \\
\text { berfikir kritis dan mendapatkan } \\
\text { persepsi baru dari satu konsep } \\
\text { atau masalah jika menggunakan } \\
\text { metode ini. }\end{array}$ & 148 & 88,1 & 20 & 11,9 \\
\hline
\end{tabular}


Lanjutan Tabel 4. Distribusi metode SCL yang diterapkan berdasarkan Persepsi Mahasiswa

\begin{tabular}{|c|c|c|c|c|c|}
\hline \multirow{2}{*}{ No. } & \multirow{2}{*}{ Pernyataan } & \multicolumn{2}{|c|}{ Positif } & \multicolumn{2}{|c|}{ Negatif } \\
\hline & & $\mathbf{n}$ & $\%$ & $\mathbf{n}$ & $\%$ \\
\hline 6. & $\begin{array}{l}\text { Saya tidak cukup percaya diri } \\
\text { untuk mengikuti diskusi jika saya } \\
\text { tidak meniliki pengetahuan yang } \\
\text { cukup tentang topik atau masalah } \\
\text { yang didiskusikan. }\end{array}$ & 130 & 77,4 & 38 & 22,6 \\
\hline 7. & $\begin{array}{l}\text { Saya merasa tertantang untuk } \\
\text { mengoreksi diri agar bisa menjadi } \\
\text { pembelajar dan individu yang } \\
\text { mandiri. }\end{array}$ & 154 & 91,7 & 14 & 8,3 \\
\hline 8. & $\begin{array}{l}\text { Mctode pembclajaran ini dapat } \\
\text { meningkatkan atau } \\
\text { membangkitkan motivasi belajar } \\
\text { saya. }\end{array}$ & 144 & 85,7 & 28 & 14,3 \\
\hline 9. & $\begin{array}{l}\text { Saya merasa jenuh dengan metode } \\
\text { pembelajaran seperti ini. }\end{array}$ & 30 & 17,8 & 138 & 82,2 \\
\hline 10. & $\begin{array}{l}\text { Memberikan pengalaman belajar } \\
\text { dan saling berbagi pengetahuan } \\
\text { menjadi ciri khas metode } \\
\text { pembelajaran ini. }\end{array}$ & 153 & 91,1 & 15 & 8,9 \\
\hline 11. & $\begin{array}{l}\text { Saya dituntut kerjasama antar } \\
\text { mahasiswa dalam memecahkan } \\
\text { suatu masalah yang dihadapi. }\end{array}$ & 155 & 92,3 & 13 & 7,7 \\
\hline 12. & $\begin{array}{l}\text { Saya mengalami kegagalan jika } \\
\text { tidak ada kerjasama dan partisipasi } \\
\text { aktif dari mahasiswa lainnya. }\end{array}$ & 129 & 76,8 & 39 & 23,2 \\
\hline 13. & $\begin{array}{l}\text { Saya merasa tertuntun untuk } \\
\text { mengembangkan kebiasaan } \\
\text { berfikir yang terkait dengan } \\
\text { pembelajaran seumur hidup dan } \\
\text { tanggungjawab sosial jika } \\
\text { menggunakan metode ini. }\end{array}$ & 148 & 88,1 & 20 & 11,9 \\
\hline 14. & $\begin{array}{l}\text { Saya merasa tepat untuk } \\
\text { meningkatkan kemampuan } \\
\text { investigasi dalam pemecahan } \\
\text { masalah yang saya hadapi. }\end{array}$ & 145 & 86,3 & 23 & 13,7 \\
\hline $15 .^{*}$ & $\begin{array}{l}\text { Saya lebih bisa jika menggunakan } \\
\text { metode yang menuntut mahasiswa } \\
\text { lebih aktif menyelesaikan masalah } \\
\text { secara mandiri. }\end{array}$ & 118 & 70,2 & 50 & 29,8 \\
\hline
\end{tabular}

Sumber: Data Primer

Pada tabel 4 terdapat 15 pertanyaan yang diajukan kepada mahasiswa, ada 3 pertanyaan yang paling banyak dipersepsi positif yakni metode small group discussion
(95,2\%); problem based learning (92,2\%); discovery learning (91,7\%) dan cooperative learning 91,1\%). 
Tabel 5. Distribusi kesukaan mahasiswa berdasarkan metode pembelajaran SCL

\begin{tabular}{|c|c|c|c|c|c|c|c|c|c|}
\hline \multirow{3}{*}{ No } & \multirow{3}{*}{ Metode SCL } & \multicolumn{4}{|c|}{2008} & \multicolumn{4}{|c|}{2009} \\
\hline & & \multicolumn{2}{|c|}{ Suka } & \multicolumn{2}{|c|}{ Tdk suka } & \multicolumn{2}{|c|}{ Suka } & \multicolumn{2}{|c|}{ Tdk suka } \\
\hline & & $\mathbf{n}$ & $\%$ & $\mathbf{n}$ & $\%$ & $\mathbf{n}$ & $\%$ & $\mathbf{n}$ & $\%$ \\
\hline 1 & Collaborative & 25 & 27,5 & 20 & 21,7 & 23 & 29,9 & 7 & 9,1 \\
\hline 2 & Cooperative & 4 & 4,4 & 11 & 12,1 & 16 & 20,8 & 7 & 9,1 \\
\hline 3 & PBL & 14 & 15,4 & 4 & 1,1 & 1 & 1,3 & 5 & 6,5 \\
\hline 4 & Project base & 6 & 6,6 & 10 & 10,9 & 6 & 7,7 & 41 & 53,3 \\
\hline 5 & Role play & 2 & 2,2 & 20 & 21,7 & 0 & 0 & 8 & 10,4 \\
\hline 6 & Small group & 4 & 4,4 & 16 & 17,6 & 17 & 22,1 & 2 & 2,5 \\
\hline 7 & Studi kasus & 35 & 38,4 & 10 & 10,9 & 13 & 16,9 & 6 & 7,8 \\
\hline \multirow[t]{2}{*}{8} & Discovery & 1 & 1,1 & 0 & 1,1 & 1 & 1,3 & 1 & 1,3 \\
\hline & Total & 91 & 100 & 91 & 100 & 77 & 100 & 77 & 10 \\
\hline
\end{tabular}

Sumber: Data Primer

Tabel 5 menjelaskan bahwa untuk pertanyaan terbuka yang menanyakan tentang metode yang paling disukai dan tidak disukai, mahasiswa angkatan 2008 memilih 3 jenis metode pembelajaran yang paling disukai yakni secara berturut -turut masing-masing studi kasus (38,4\%); metode kolaboratif (27,5\%) dan metode PBL ( $15,4 \%)$. Sedangkan yang paling tidak disukai adalah metode kolaboratif $(21,7 \%)$; role play $(21,7 \%)$ dan small group (17,6\%).
Adapun angkatan 2009, yang paling disukai adalah metode kolaboratif, small group dan kooperatif dengan persentase masing-masing (29,9\%); (22,\%) dan (20,8\%). Sedangkan metode yang paling tidak sukai adalah masing-masing secara berturut-turut project base $(53,3 \%)$; role play $(10,4 \%)$ dan kooperatif dan kolaboratif masingmasing (9,1\%).

4. Gambaran persepsi tenaga kependidikan terhadap metode pembelajaran SCL

Tabel 6. Komentar informan terhadap metode pembelajaran SCL

\begin{tabular}{ll}
\multicolumn{1}{c}{ Pertanyaan } & \multicolumn{1}{c}{ Pendapat Informan } \\
\hline Apakah bapak/ ibu pcrnah & 1. "tidak pak " (11) \\
mendengar istilah student & 2. "surat-surat" (I2,I3) \\
centered leurning (SCI)? & 3. "dari koran identitas dan pernah mendengar dari Pak \\
& 4. "dari rapat-rapat" (I4, I5) \\
\hline Dari siapa Bapak/Ibu & 1. "surat-surat...." (I2,I3) \\
mendengar istilah tersebut? & 2. "baca dari koran identitas dan mendengar dari Pak Dadang \\
& 3. "di rapat." (I4, I5) \\
\hline Apakah Bapak/Ibu tahu & 1. "; iya,..." (I7) \\
tentang SCL? & 2. "saya tahu itu..(I4) \\
& 3. "sama sekali pak saya belum pernah dengar"(I5) \\
& 4. "tidak terlalu tahu juga pak..."(I2) \\
\hline
\end{tabular}


Pertanyaan

Apa yang Bapak/Ibu tahu tentang SCL?

\section{Pendapat Informan}

1. “pembelajaran berdasarkan komputer." (I7)

2. "SCL itu artinya ruangannya kecil

3. "(I4)

4. “...semacam fgd, jumlah kelasnya kecil, (I2)

Apa manfaat SCL?

1. ".mengembangkan potensi dan motivasi mahasiswa" (I7)

2. "mahasiswa lebih aktif mencari dan menerima" (I2)

3. "memberikan peluang kepada mahasiswa untuk leb ih banyak sumber yang diperoleh, memudahkan mahasisswa untuk mencari materi perkuliahan ini" (I4)

4. ".mahasiswa lebih serius dalam mata kuliahnya" (I5)

5. " mahasiswa lebih aktif dalam kuliah" (I1)

6. " mahasiswa semakin mandiri" (I6)

Apa upaya Bapak/Ibu untuk membantu pelaksanaan SCL?

1. "memfasilitasi, ruangan, peraga dan LCD..."(I7)

2. "memperlancar proses administrasinya..."(I4)

3. “sarana dan prasarana"(I5)

4. "memantau dan memonitoring"(I6)

Menurut apak/Ibu apa yang harus dilakukan oleh dosen utk pelaksanaan SCL?

1. “.dosen itu jarang kasih masuk apa topiknya. Ada juga yang kasih masuk tapi tidak bisa terbaca" (I6)

2. “.draft atau pertemuan seperti itu dan perlu diketahui tentang metode apa itu" (I2)

3. "harusnya dia melaporkan supaya disusun jadwal ke pihak akademik ..."(I7)

4. "para pendidik juga harus on time agar tidak mempcrsulit jika berpindah-pindah sehingga tidak molor kuliahnya..."(I5)

Menurut Bapak/Ibu apa yang harus dilakukan oleh mahasiswa utk pelaksanaan SCL?

Sumber: Data Primer
1. "mahasiswa harus lebih aktif."(I5)

2. "mahasiswa harus siap dengan banyaknya tugas"(I2)

3. "lebih ke mentalnya saja"(I)
Pada tabel 6 sebanyak 8 pertanyaan yang diajukan kepada 7 orang informan pada saat FGD sebagai pedoman wawancara, yakni apakah pernah mendengar istilah SCL, dari siapa, apakah tahu tentang SCL, apa saja yang diketahui, manfaat SCL, upaya yang dilakukan untuk pelaksanaan SCL, upaya yang harus dilakukan oleh dosen dalam pelaksanaan SCL dan upaya yang dilakukan oleh mahasiswa pada pelaksanaan SCL.

Informan yang dilibatkan terdiri dari kepala tata usaha sebagai informan kunci, kepala sub bagian akademik, kepala sub bagian perlengkapan, kepala sub bagian kemahasiswaan, pegawai bagian monitoring dan evaluasi serta pegawai bidang perencanaan akademik serta staf keuangan.
Umumnya informan mengetahui dan mendengar istilah SCL melalui surat menyurat, surat kabar kampus dan rapat-rapat. Informan mengartikan SCL sebagai pembelajaran dengan komputer, ruangan kecil atau semacam FGD. Dalam hal manfaat SCL, informan mengartikannya sangat variatif seperti mengembangkan potensi dan motivasi mahasiswa; mahasiswa lebih aktif mencari dan menerima, memberikan peluang kepada mahasiswa untuk lebih banyak sumber yang diperoleh, memudahkan mahasiswa untuk mencari materi perkuliahan ini; mahasiswa lebih serius dalam mata kuliahnya; mahasiswa lebih aktif dalam kuliah; mahasiswa semakin mandiri.

Ketika ditanyakan tentang upaya yang dilakukan untuk pelaksanaan SCL, umumnya menjawab: memfasilitasi, 
ruangan, peraga, $\mathrm{LCD}$, memperlancar proses administrasinya, sarana dan prasarana, memantau dan memonitoring.

Sedangkan upaya yang perlu dilakukan oleh dosen adalah memasukkan topik beserta dengan metode pembelajaran dan on time dalam pelaksanaan perkuliahan. Untuk mahasiswa, harus lebih aktif, siap banyak tugas dan memperbaiki mental.

Pengetahuan adalah segala sesuatu yang diketahui karena mempelajari ilmu, mengalami, melihat dan mendengar. ${ }^{2}$ Pengetahuan merupakan hasil yang berasal dari proses penginderaan terhadap objek tertentu. Proses penginderaan terjadi melalui panca indera manusia, yakni indera penglihatan, pendengaran, penciuman, rasa dan melalui kulit.

Pengetahuan atau kognitif merupakan domain yang sangat penting dalam membentuk tindakan seseorang (overt berhavior). Pengukuran pengetahuan dapat dilakukan dengan wawancara atau angket yang menanyakan tentang isi materi yang ingin diukur dari subyek penelitian atau responden. ${ }^{1}$

Hasil penelitian ini memberikan gambaran bahwa pengetahuan dosen Program Studi Ilmu Gizi Fakultas Kesehatan Masyarakat Unhas seperti yang tergambar pada tabel 1 bahwa diantara 16 pertanyaan yang disajikan dalam kueisioner kepada dosen pengampu mata kuliah, ternyata ada 3 metode pembelajaran yang paling banyak dijawab benar oleh responden diantaranya small group, cooperative learning dan problem based learning.

Terpilihnya ketiga metode pembelajaran tersebut mungkin disebabkan karena ketiganya memiliki kemiripan aktifitas dosen seperti (1) mempersiapakan diri dan materi diskusi; (2) membuka perkuliahan (menjelaskan tujuan diskusi dan pokok-pokok masalah); (3) mengarahkan jalannya diskusi; (4) memberi kesempatan bertanya kepada mahasiswa; (5) mengevaluasi kegiatan diskusi dan (6) memberi umpan balik secara umum tentang jalannya proses diskusi dan capaian hasil kegiatan diskusi serta (7) menutup kegiatan perkuliahan.

Sebagai salah satu wujud tanggung jawab atas kewajibannya, dosen dituntut memilih metode pembelajaran yang paling akomodatif dan kondusif untuk mencapai sasaran dan filosofi pendidikan. Beberapa contoh sasaran pembelajaran adalah mendapatkan pengetahuan; mengembangkan konsep; memahami teknik analisis; mendapatkan skill dalam menggunakan konsep dan teknik; mendapatkan skill dalam memahami dan menganalisis masalah; mendapatkan skill dalam mensintesis rencana kegiatan dan implementasi; mengembangkan kemampuan untuk berkomunikasi; mengembangkan kemampuan untuk menjalin hubungan saling percaya; mengembangkan tertentu; mengembangkan kualitas pola pikir; mengembangkan judgment dan wisdom. ${ }^{11}$

Hasil penelitian ini juga menggambarkan bahwa ketika dosen ditanya tentang metode pembelajaran yang paling disukai, ternyata metode small group discussion dan studi kasus dipilih paling banyak yakni masing-masing masingmasing 4 orang (18,2\%). Dalam pelaksanaan metode small group dosen memang relatif gampang melaksanakannya. Kegiatan dosen dalam metode small group menjelaskan tujuan diskusi; mengarahkan jalannya diskusi; memberikan kesempatan bertanya kepada mahasiswa; mengevaluasi dan menutup diskusi ${ }^{7}$

Banyaknya dosen yang menjawab benar kelebihan metode small group $(54,5 \%)$ berbanding lurus dengan tingkat kesukaan pilihan metode pembelajaran yakni (18,2\%). Sedangkan metode problem based learning (PBL) meskipun disukai oleh 13,6\% dosen namun terdapat 95,5\% dosen menjawab salah ketika ditanyakan tentang kelebihan metode PBL, sebaliknya ketika ditanyakan tentang kelemahan metode PBL ternyata ada 54,5\% dosen yang menjawab secara benar.

Begitu pula dengan metode pembelajaran yang tidak disukai, ada 6 dosen $(27,3 \%)$ dosen yang tidak memberikan jawaban. Banyaknya dosen yang tidak memberikan jawaban terhadap pertanyaan metode yang tidak disukai kemungkinan disebabkan karena metode yang dipakai di prodi ilmu gizi FKM Unhas bisa lebih dari satu metode pada satu mata kuliah. Misalnya mata kuliah manajemen layanan makanan institusi yang menggunakan 4 jenis metode sekaligus yakni collaborative learning, project based leaming, cooperative learning dan problem based learning.

Sedangkan metode cooperative learning dan discovery learning tidak disukai oleh masing-masing oleh 3 orang $(13,6 \%)$. Ketidaksukaan terhadap metode cooperative learning dan discovery learning karena memang ada masing-masing 40,9 
$\%$ dosen yang tahu persis tentang kelemah-an metode cooperative learning dan (36,4\%) discovery learning.

Dalam penelitian ini persepsi mahasiswa mengenai ragam metode pembelajaran SCL diukur dengan pernyataan yang terkait dengan metode pembelajaran yang pernah dilatihkan oleh dosen pengampu mata kuliah.

Ada 15 item pernyataan yang merupakan rangkuman dari 8 jenis metode pembelajaran yakni (item 1 dan 3 untuk pernyataan metode role play); pernyataan $(6,7,15)$ untuk metode discovery learning; pernyataan (11 dan 14) untuk metode problem based learning; pernyataan 2, 10 dan 12 ) untuk metode koperatif; pernyataan (5 dan 13 ) untuk metode studi kasus; pernyataan (4) untuk metode kolaboratif dan pernyataan (8,dan 9) untuk metode project based.

Selain pernyataan itu, juga diberikan pertanyaan terbuka tentang metode pembelajaran yang disukai dan tidak disukai oleh mahasiswa. Kedua komponen tersebut merupakan bagian yang akan dibahas keterkaitan antara pernyataan persetujuan atau ketidaksetujuan dengan kesukaan atau ketidaksukaan terhadap metode pembelajaran yang disajikan oleh dosen pengampu mata kuliah.

Dari hasil penelitian ini menggambarkan bahwa diantara 15 item pernyataan yang diberikan kepada mahasiswa ternyata hanya satu item yakni item (9) yang kurang disetujui oleh mahasiswa yakni sebanyak $82,1 \%$, sedangkan item yang paling disetujui oleh oleh mahasiswa adalah item (2) sebanyak 95,2\% dan menyusul iterm (11) sebanyak $92,2 \%$ dan item (7) dengan $91,6 \%$.

Banyaknya mahasiswa yang tidak setuju dengan item (9) yang merupakan rangkuman dari metode discovery learning mungkin disebabkan karena dalam penerapannya membutuhkan biaya pengembangan yang tinggi dan butuh waktu lama. Metode ini juga mempunyai kelemahan karena dapat menyebabkan terjadinya kejenuhan berfikir, potensi kesalahan persepsi yang besar dan dosen bisa gagal dalam mendeteksi masalah dan kesalahan persepsi yang terjadi di kalangan mahasiswanya .
Berbeda dengan item (2) yang merupakan intisari dari metode pembelajaran cooperative learning, lebih banyak disetujui oleh mahasiswa mungkin karena metode tersebut melibatkan mahasiswa secara aktif dan terjadi interaksi kelompok dalam proses pelaksanaannya. Meskipun metode ini disetujui oleh banyak mahasiswa namun ketika ditanyakan tingkat kesukaan terhadap metode tersebut sebagaimana tergambar pada (tabel 4) ternyata hanya 20 (11,9\%) mahasiswa yang memilihnya dan yang tidak menyukainya ada $18(10,7 \%)$ mahasiswa.

Untuk item (11) yakni intisasri dari metode problem based learning (PBL) disetujui oleh $(92,2 \%)$ dan disukai oleh $8.9 \%$ mahasiswa. Hanya 5,3\% mahasiswa yang tidak menyukai metode pembelajaran PBL.

Urutan berikutnya adalah item (7) yang memuat tentang metode discovery learning disukai oleh 91,6\% tetapi tidak satu pun mahasiswa yang memilihnya sebagai metode yang disukai maupun tidak disukai. Tidak adanya mahasiswa yang memilih metode ini mungkin disebabkan karena tidak ada satu pun matakuliah gizi yang menggunakan metode tersebut, meskipun pada saat pelatihan SCL metode tersebut tetap disajikan oleh narasumber.

Metode pembelajaran yang paling disukai oleh mahasiswa adalah role play yakni 35 orang $(20,8 \%)$ namun disetujui oleh $89,9 \%$ dan 65,5\% (item 1 dan 3). Ada $29(17,3 \%)$ mahasiswa tidak menyukai metode role play dan tidak disetujui oleh masing $10,1 \%$ dan $34,5 \%$ oleh mahasiswa (item 1 dan 3).

Dalam hal persepsi tenaga kependidikan terhadap pelaksanaan metode pembelajaran SCL adalah pandangan, kesan dan interpretasi tenaga kependidikan terhadap pelaksanaan metode pembelajaran SCL di program Studi Ilmu Gizi FKM Unhas.

Dari hasil FGD tergambar bahwa informan yang diwawancarai sangat kurang informasi yang benar tentang metode pembelajaran SCL. Bahkan ada diantara informan yang tidak pernah mendengar tentang istilah SCL. Diantara yang pernah mendengar istilah SCL, ada diantaranya yang lewat surat menyurat, ada juga yang membaca lewat surat kabar kampus dan yang lainnya melalui rapat-rapat. 
Hasil penelitian ini menunjukan bahwa tenaga kependidikan tidak pernah dilibatkan secara langsung dalam proses penentuan metode pembelajaran SCL, baik di tingkat fakultas maupun di program studi. Tidak adanya keterlibatan tenaga kependidikan, mengakibatkan informan mempersepsi SCL berdasarkan kesan, atau interpretasi mereka sendiri, dan persepsi mereka ternyata sangat superfisial bahkan ada yang keliru mempersepsi istilah SCL, sebagaimana pernyataan informan (I7, I4 dan I2) secara berturut-turut menyatakan bahwa: iya saya tahu SCL, pembelajaran berdasarkan komputer(I7); SCL itu artinya ruangan kecil (I4); SCL itu semacam FGD; jumlah kelasnya kecil (I2).

Hasil penelitian ini juga mengkonfirmasi bahwa persepsi tenaga kependidikan terhadap metode pembelajaran SCL dalam hal manfaat SCL sangat variatif sebagaimana diungkapkan oleh masing-masing informan sebagai berikut: mengembangkan potensi dan motivasi mahasiswa (I7); mahasiswa lebih aktif mencari dan menerima (I2); memberikan peluang kepada mahasiswa untuk lebih banyak sumber yang diperoleh; memudahkan mahasiswa untuk mencari materi perkuliahan (I4); mahasiswa lebih serius dalam mata kuliahnya (I5); mahasiswa lebih aktif dalam kuliah (11) dan mahasiswa semakin mandiri (I6).

Hasil penelitian ini, memberikan gambaran bahwa tenaga kependidikan sebenarnya telah ber-partisipasi dalam pelaksanaan pembelajaran metode SCL sebagaimana yang tergambar pada pernyataan mereka tentang upaya membantu pelaksanaan SCL. Informan mempunya persepsi bahwa keterlibatan mereka dapat berupa: memfasilitasi ruangan, peraga dan LCD (I7), memperlancar proses administrasi, sarana dan prasarana dan memantau dan memonitoring. Kesediaan membantu pelaksanaan pembelajaran SCL rupanya sangat terkait dengan tupoksi mereka masing-masing.

Karena tenaga kependidikan tidak dilibatkan dalam proses penyusunan pelaksanaan metose SCL, sehingga berimplikasi pada persepsi mereka tentang upaya yang harus dilakukan oleh dosen dan mahasiswa dalam pelaksanaan SCL. Informan menganggap bahwa seharusnya dosen memasukan topik setiap mata kuliah yang diajarkan namun kenyataannya, dosen jarang memasukkan topik mata kuliahnya bahkan ada yang tidak memasukkan topik, sehingga menyulitkan bagian akademik menyusun jadwal perkuliahan yang menggunakan metode SCL (I6). Meskipun ada juga dosen yang memasukkan topik mata kuliah, namun tidak mencantumkan metode SCL yang digunakan pada saat mengajar dan tidak melaporkan kepada bagian akademik (I2 dan I7). Selain itu, tenaga kependidikan juga berharap bahwa dosen perlu on time dan tidak memindahkan jadwal mengajarnya karena biasanya berimplikasi pada molornya perkuliahan (I5).

Tenaga kependidikan berpersepsi bahwa sebaiknya mahasiswa lebih aktif mengikuti perkuliahan dan siap mendapatkan banyak tugas dari dosen serta memperbaiki mentalitas.

\section{KESIMPULAN}

Pengetahuan dosen program studi ilmu gizi terhadap penerapan metode pembelajaran SCL belum merata. Persepsi mahasiswa umumnya positif terhadap metode pembelajaran SCL dan persepsi tenaga kependidikan FKM Unhas terhadap penerapan metode pembelajaran SCL pada umumnya kurang mengerti.

\section{SARAN}

Perlu pelatihan sebagai bentuk penyegaran kepada dosen, melibatkan tenaga kependidikan program studi ilmu gizi penerapan metode pem-belajaran SCL. Tenaga kependidikan perlu dilibatkan dalam proses penyusunan metode pembelajaran SCL dan perlu penelitian lebih lanjut secara spesifik terhadap masing-masing metode pembelajaran SCL.

\section{DAFTAR PUSTAKA}

1. Notoatmodjo, S. Pengantar pendidikan kesehatan dan ilmu perilaku kesehatan, Penerbit Andi Offset, Yogyakarta; 1993: 37-8.

2. Purwodarminto, WJS. Kamus umum bahasa Indonesia, Balai Pustaka, Jakarta; 1999.

3. Sari D.N, et.al. Tingkat persepsi mahasiswa prodi pendidikan dokter Fakultas Kedokteran UGM terhadap situasi pembelajaran studi berdasarkan DREEM, Jurnal Pendidkan Kedokteran Indonesia; 2008; 3(4): 146.

4. Pongtuluran, A. Student centered learning: The urgency and possibilities [Inter-net]. [Cited] $2013 \mathrm{Feb}$ 20]. Available from Uripsantoso.files.wrdpress. com. 
5. Herreid, C.F. The use of case studies and group discussion in science education. University of Buffalo, State University of New York. 2007.

6. Herreid, C.F. The Use of Case Studies and Group Discussion. In Science Education. University of Buffalo, State University of New York. 2007.

7. Hudecki, M.S. A Case Study of Memory Loss in Mice. Departemen of Biological Sciences University of Buffalo, state University of New York. 2007.

8. Bruner, J. Discovery learning at learning theories. 2007.
9. Smith BL, MacGregor JT. What is collaborative learning. In: Goodsell A, Maher M, Tinto V, Smith BL, MacGregor JT. Collaborative learning: A Sourcebook for higher education. National Centre, Pennsylvania; 1992.

10. White, H.B. 2005. Problem Based Learning. 2007.

11. Handoko, H. Metode Kasus dalam Pengajaran (Manajemen), Makalah disampaikan pada lokakarya Peningkatan Kemampuan Penyusunan dan Penerapan Kasus untuk Pengajaran, Semarang 23 November 2005. 